\title{
ANALISIS KNOWLEDGE MANAGEMENT SYSTEM PADA SISTEM INFORMASI PESONA WISATA BANYUMAS
}

\section{KNOWLEDGE MANAGEMENT SYSTEM ANALYSIS IN BANYUMAS TOURISM INFORMATION SYSTEM}

\author{
Pungkas Subarkah $^{1^{*}}$, Debby Ummul Hidayah ${ }^{2}$ \\ ${ }^{1,2}$ Universitas Amikom Purwokerto, Jl. Let. Jend. Pol. Soemarto, Purwokerto, Banyumas \\ *E-mail: subarkah@amikompurwokerto.ac.id
}

\begin{abstract}
ABSTRAK
Perkembangan teknologi jaman sekarang semakin meningkat, sehingga kebutuhan dalam mendapatkan sebuah informasi juga semakin meningkat baik dari segi akurasi maupun segi efisiensi waktu. Oleh karena itu sebuah informasi menjadi sesuatu yang bernilai dan dibutuhkan salah satunya di bidang pariwisata. Pengetahuan sangat diperlukan ketika bepergian atau berwisata baik untuk mengetahui lokasi pada aplikasi Pesona Wisata Banyumas. Penelitian ini bertujuan untuk memberikan informasi kepada masyarakat luas dan mempromosikan tentang objek wisata dan informasi lokasi pariwisata yang ada di Kabupaten Banyumas. Pengetahuan Objek wisata saat ini menjadi peran penting baik bagi masyarakat di daerah pedesaan maupun kota. Metode yang digunakan dalam peneliian ini yaitu pengembangan sistem yang diadopsi dari Knowledge Management System Life Cycle (KMSLC) terdiri dari Evaluae Existing Infrastructure, Knowledge Capture dan Implement the KM System. Dengan adanya Knowledge Management System pada sistem informasi Pesona Wisata Banyumas, maka dapat membantu pengunjung untuk menentukan lokasi dan tujuan wisata yang tepat. Penelitian dilakukan dengan Knowledge Capture atau pemetaan pengetahuan pada aplikasi. Hasil penelitian ini, sistem informasi Pesona Wisata Banyumas sangat membantu wisatawan untuk mencari informasi mengenai wisata yang ada ada di Kabupaten Banyumas. Dari pihak pengelola wisata juga terbantu karena wisatanya lebih terekspos dan tersebar luas sehingga banyak masyarakat yang tahu tentang wisata dan datang berkunjung ke wisata tersebut.
\end{abstract}

Kata kunci: Knowledge management system, pengetahuan, Pesona Wisata Banyumas, Knowledge Management System Life Cycle (KMSLC), knowledge capture

\begin{abstract}
The development of today's technology is increasing, so the need to get information is also increasing both in terms of accuracy and in terms of time efficiency. Therefore, an information becomes something of value and one of them is needed in the field of tourism. Knowledge is needed when traveling or traveling either to find out the location on the Pesona Wisata Banyumas application. This study aims to provide information to the wider community and promote tourism objects and information on tourism locations in Banyumas Regency. Knowledge of tourism objects is currently an important role for people in rural and urban areas. The method used in this research is the development of a system adopted from the Knowledge Management System Life Cycle (KMSLC) consisting of Evaluate Existing Infrastructure, Knowledge Capture and Implementing the KM System. With the Knowledge Management System in the Pesona Wisata Banyumas information system, it can help visitors to determine the right location and tourist destination. The research was conducted using Knowledge Capture or knowledge mapping on the application. The results of this study, the Pesona Wisata Banyumas information system really helps tourists to find information about tourism in Banyumas Regency. From the tourism manager, it is also helped because the tourism is more exposed and widespread so that many people know about tourism and come to visit the tour.
\end{abstract}

Keywords: Knowledge management system, pengetahuan, Pesona Wisata Banyumas, Knowledge Management System Life Cycle (KMSLC), knowledge capture

\section{PENDAHULUAN}

Perkembangan teknologi zaman sekarang sudah semakin meningkat, sehingga kebutuhan dalam mendapatkan sebuah informasi juga semakin meningkat baik dari segi akurasi maupun segi efisiensi waktu. Dalam mengikuti pertumbuhan suatu informasi, tentu tidak hanya langsung menerapkannya 
tetapi harus melalui adanya suatu proses pengolahan serta pemanfaatan informasi yang ada. Sehingga sebuah informasi menjadi sesuatu yang bernilai. Oleh sebab itu dibutuhkan suatu konsep yang dikenal dengan knowledge management, dengan demikian penerapan pengetahuan benar-benar tertata [1]. Pengetahuan sangat diperlukan ketika hendak bepergian atau berwisata seperti untuk mengetahui lokasi pariwisata yang menarik melalui tampilan gambar pada aplikasi. Banyumas merupakan tempat yang memiliki banyak tempat pariwisata yang indah untuk dikunjungi wisatawan. Banyak macam pariwisata yang ada seperti Curug, Baturraden, Batur Agung, bukit, Bendungan Gerak Serayu, goa, museum, dan lain sebagainya yang dapat menarik pengunjung atau wisatawan untuk mengisi liburan. Penelitian sebelumnya yaitu [2] dengan judul "Knowledge Management System pada Biro Administrasi Akademik Akademi Pariwisata Nusantara". Pada penelitian ini, penulis mencoba mengembangkan model knowledge management system yang sesuai dengan kondisi yang ada pada Biro Administrasi Akademik Akademi Pariwisata Nusantara. Metodologi dalam penelitian ini menggunakan kerangka kerja model SSM, pembentukan knowledge menggunakan model SECI. Metode yang digunakan dalam merancang sistem adalah menggunakan Unified Modelling Language (UML) dan teknik pengujian fungsional sistem menggunakan metode FGD. Hasil yang didapatkan dari penelitian ini adalah prototype knowledge management system yang dapat menyimpan pengetahuan dan pengalaman karyawan dengan baik sehingga menjadi sebuah solusi untuk berbagi sharing knowledge dan dapat mendukung kinerja karyawan di Biro Administrasi Akademik Pariwisata Nusantara. Dengan latar belakang ini penulis mengambil judul "Analisis Knowledge Management System Informasi Pesona Wisata Banyumas". Pada penelitian ini, penulis hanya menganalisis KMS pada aplikasinya saja.

Pengetahuan terdiri dua jenis yaitu pengetahuan tacit dan pengetahuan explicit. Menurut [3] pengetahuan tacit merupakan wawasan dan pengalaman yang ada pada individu yang tidak diketahui bahwa mereka menggunakannya secara aktif atau pengetahuan yang berupa pengalaman yang ada pada setiap individu. Sedangkan pengetahuan explicit adalah pengetahuan yang secara rasional dapat dinyatakan dalam kata-kata, kalimat, angka atau formula yang dituangkan dalam bentuk buku, dokumen, jurnal dan lainlain [4]. Pengetahuan adalah kejelasan dari data dan informasi menjadi konteks teknologi informasi sehingga pengetahuan tersebut disimpan dalam bentuk digital [5]. Disamping itu pengetahuan merupakan informasi yang dimiliki oleh individu dalam organisasi yang pada akhirnya bisa bermanfaat bagi orang lain [6]. Pengetahuan adalah sumber keunggulan kompetitif yang memberikan prioritas tinggi untuk memastikan bahwa mereka mendapatkan manfaat maksimal dan memperoleh pengetahuan dimana pengetahuan dibangun dari data dan data sendiri merupakan fakta hasil observasi atau persepsi [7]. Selain itu pengetahuan merupakan aset intelektual dimana pengetahuan mempunyai karakteristik seperti penggunaan pengetahuan tidak akan habis, transfer pengetahuan tidak ada batas dan jumlah pengetahuan yang berlimpah tetapi dibatasi maka akan hilang begitu saja sehingga diperlukan media untuk berbagi pengetahuan [8].

Representasi pengetahuan yaitu metode yang digunakan sebagai cara perolehan pengetahuan dari para pakar. Proses representasi dalam format data supaya mudah dipahami oleh manusia menggunakan komputer sehingga memudahkan dalam pengambilan keputusan [5].

Manajemen pengetahuan merupakan hasil maksimal dari sumber pengetahuan yang dibutuhkan oleh seseorang [9]. Manajemen pengetahuan juga merupakan proses pengelolaan pengetahuan dengan cara penangkapan, penyimpanan, dan penyebaran pengetahuan dengan menggunakan media teknologi informasi [10]. Disamping itu manajemen pengetahuan merupakan bidang studi yang dapat meningkatkan proses berbagi, penyaluran, menciptakan, menangkap, dan pemahaman pengetahuan sehingga pengetahuan tersebut tidak sia-sia [2]. Manajemen Pengetahuan terdiri dari sistem perangkat lunak serta mengintegrasikan dan menyebarkan informasi bagi pengguna untuk proses pembelajaran dan membuat keputusan.

Sistem manajemen pengetahuan adalah integrasi teknologi dan mekanisme yang dikembangkan untuk mendukung proses manajemen pengetahuan [9]. Sistem manajemen pengetahuan dapat diklasifikasikan ke dalam empat jenis yaitu aplikasi pengetahuan, menangkap pengetahuan, berbagi pengetahuan, penemuan pengetahuan, maka 
pengetahuan yang terdapat pada sistem tersebut bisa digunakan sesuai dengan bidangnya masing-masing.

Menangkap pengetahuan bukanlah tugas yang mudah. Pengetahuan yang diambil bisa berupa dokumen- dokumen atau pengetahuan dari para pakar. Salah satu definisi menangkap pengetahuan yaitu transfer pengetahuan dari para pakar ke dalam sebuah program [11]. Teknik yang digunakan untuk menangkap pengetahuan yaitu On-Site Observation artinya pengamatan yang dilakukan dengan cara menafsirkan dan merekam untuk memecahkan suatu masalah atau pengamatan di lapangan dengan membawa pengembang lebih dekat pada langkah nyata, teknik, dan prosedur yang digunakan.

Kodifikasi pengetahuan berarti mengkonversi pengetahuan tacit ke dalam bentuk pengetahuan explicit yang digunakan oleh para anggota organisasi [11]. Alat atau prosedur pengetahuan terdiri dari (1) Knowledge Map merupakan sebuah representasi visual dari suatu pengetahuan yang saling terhubung antara satu dengan yang lain dalam suatu rangkaian proses; (2) Frames merupakan kodifikasi pengetahuan melalui pengalaman sebelumnya; (3) Production Rules merupakan representasi dari pengetahuan yang merupakan bentuk populer dari pengetahuan tacit. Rule yang digunakan berupa pernyataan yang menentukan tindakan yang akan diambil dalam kasus tertentu. Sintaksnya adalah IF(premise) THEN (action); (4) Case-Based Reasoning merupakan kumpulan kasus yang dipecahkan dengan melibatkan pakar. Mendokumentasikan banyak kasus sehingga bisa digunakan ketika terdapat kasus yang mirip.

\section{METODOLOGI}

Metodologi menguraikan tentang bahan dan peralatan utama, serta metode penelitian yang digunakan, serta memberikan rincian memadai yang memungkinkan penelitian untuk diulang kembali. Metode yang sudah diterbitkan harus ditunjukkan dengan referensi. Penulisan bahan dan peralatan utama diuraikan secara ringkas dan jelas berbentuk paragraf.

Metode yang digunakan yaitu metode yang diadopsi dari KM System Life Cycle yang terdapat pada Awad dan Ghaziri second Edition [11]. Metode pada Gambar 3.1 terdiri dari Evaluate Existing Infrastructure, Knowledge Capture, Implement the KM system.

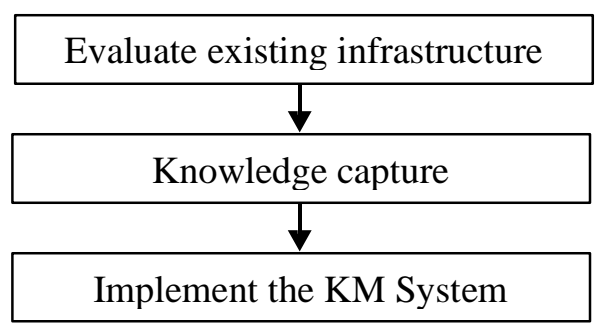

Gambar 1. KMS life cycle

1. Evaluate Existing Infrastructure

Proses evaluate existing infrastructure ini merupakan tahap pertama KM System Life Cycle. Proses ini dilakukan dengan cara menganalisis kebutuhan sisten yang akan dirancang.

2. Knowledge Capture

Knowledge capture dilakukan dengan cara membuat map pengetahuan pada system. Dimana setiap mapnya terintegrasi dan saling berhubungan.

3. Implement the KM system

Implement the KM system dilakukan dengan cara melakukan screenshot sistem

\section{HASIL DAN PEMBAHASAN}

1. Evaluate Existing Infrastructure

Kebutuhan sistem yang akan dirancang yaitu melalui pengumpulan data tentang daftar wisata alam, di daerah Kabupaten Banyumas.

2. Knowledge Capture

Map pengetahuan yang dirancang pada system ini terdiri dari:

a. Knowledge Map Daftar Wisata Alam Knowledge Map daftar wisata alam Kabupaten Banyumas seperti pada Gambar 2 di bawah ini:

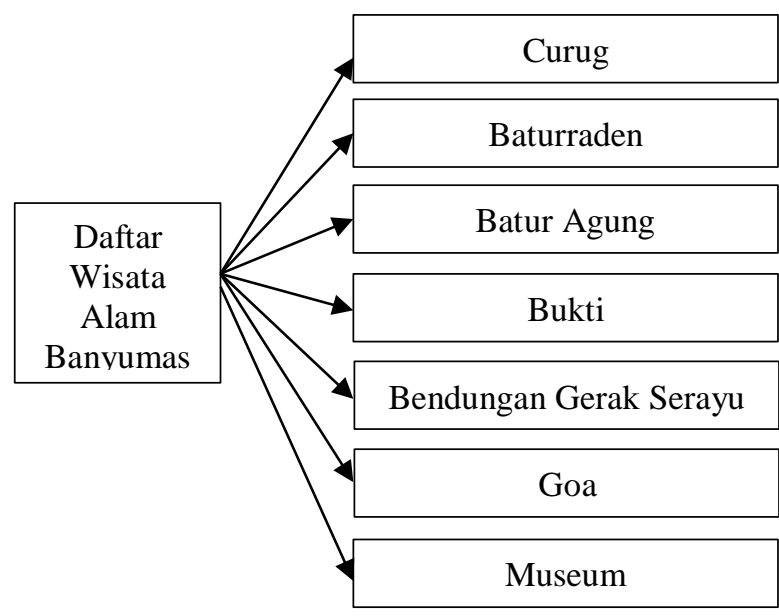

Gambar 2. KM map daftar wisata alama Kabupaten Banyumas 
b. Knowledge Map Tentang Kabupaten Banyumas Knowledge map tentang kabupaten Banyumas yaitu seperti Gambar 3 di bawah ini :

\begin{tabular}{|c|c|}
\hline $\begin{array}{c}\text { Tentang Kabupaten } \\
\text { Banyumas }\end{array}$ & $\begin{array}{c}\text { Informasi Seputar } \\
\text { Kabupaten } \\
\text { Banyumas }\end{array}$ \\
\hline
\end{tabular}

Gambar 3. Knowledge map tentang Kabupaten Banyumas

3. Implement The KM System

Dalam implementasi KM System ini dilakukan menggunakan hardware dan software dengan spesifikasi seperti di bawah ini :

a. Spesifikasi Hardware
1) Laptop seri Asus A456U
2) Processor Intel $\AA$ Core ${ }^{\mathrm{TM}}$ i5- $7200 \mathrm{U}$
3) RAM 4,00 GB DDR4
4) System Type 64-bit Operating System

b. Spesifikasi Software

1) Sistem Operasi Windows 10

2) Android Studio

3) Android SDK dan ADT Plugin

4) Adobe Photoshop CS3

5) Microsoft Office 2013

6) Sistem Operasi Android Nougat 7.1.1

c. Hasil Tampilan

Tampilan hasil sistem informasi Pesona Wisata Banyumas terlihat pada gambar seperti di bawah ini:

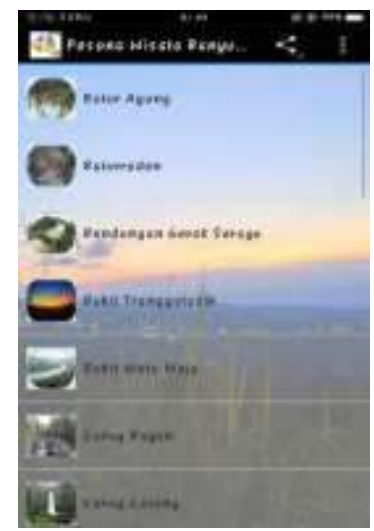

Gambar 4. Tampilan sistem pesona wisata Banyumas (daftar wisata 1)
Dari gambar 4 dapat dijelaskan bahwa tampilan sistem informasi Pesona Wisata Banyumas tersebut berisi tentang informasi daftar wisata alam yang ada di Kabupaten Banyumas seperti lokawisata Batur Agung, Baturaden, bendungan Gerak Serayu, Bukit Watu Meja, Curug Bayan, Curug Ceheng.

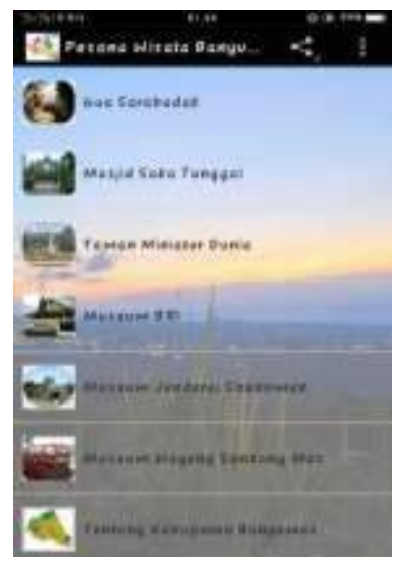

Gambar 5. Tampilan sistem pesona wisata Banyumas (daftar wisata 2)

Dari gambar 5 dapat dijelaskan bahwa tampilan sistem informasi Pesona Wisata Banyumas tersebut berisi tentang informasi daftar wisata alam yang ada di Kabupaten Banyumas lanjutan dari gambar 4.3 yaitu seperti lokawisata Gua Sara Badak, Masjid Saka Tunggal,Taman Miniatur Dunia, Museum BRI, Museum Jendral Soedirman, Museum Wayang Sendang Mas, Tentang Kabupaten Banyumas.

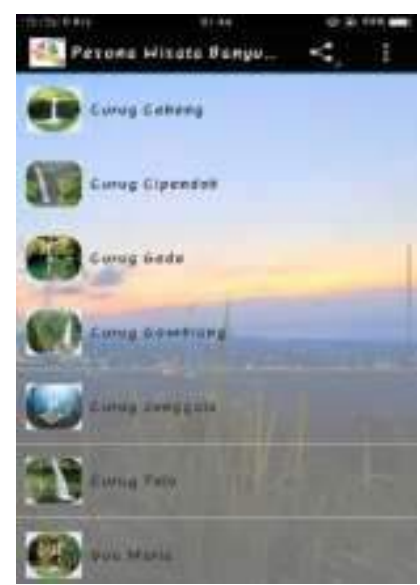

Gambar 6. Tampilan sistem pesona wisata Banyumas (daftar wisata 3) 
Dari gambar 6 dapat dijelaskan bahwa tampilan sistem informasi Pesona Wisata Banyumas tersebut berisi tentang informasi daftar wisata alam yang ada di Kabupaten Banyumas lanjutan dari gambar 4.4 yaitu seperti lokawisata Curug Ceheng, Curug Cipendok, Curug Gede, Curug Gomblang, Curug Jenggala, Curug Telu, Gua Maria.

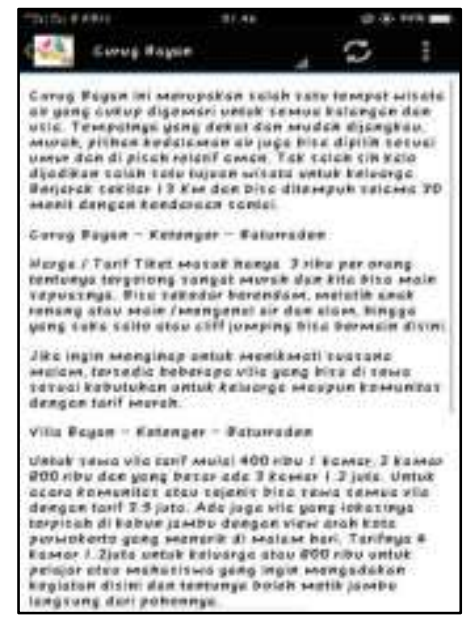

Gambar 7. Tampilan sistem pesona wisata Banyumas (informasi wisata)

Dari gambar 7 dapat dijelaskan bahwa tampilan sistem informasi Pesona Wisata Banyumas tersebut berisi tentang informasi dari salah satu wisata alam yang ada di Kabupaten Banyumas, yaitu informasi dan penjelasan mengenai wisata Curug bayan.

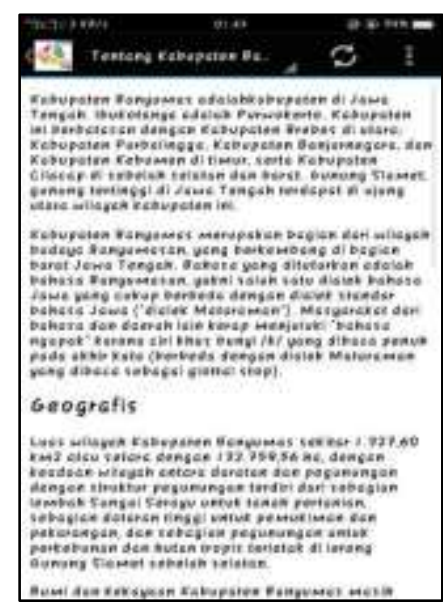

Gambar 8. Tampilan sistem pesona wisata Banyumas (informasi Kabupaten Banyumas)
Dari gambar 8 dapat dijelaskan bahwa tampilan sistem informasi Pesona Wisata Banyumas tersebut berisi tentang informasi dari Kabupaten Banyumas.

\section{KESIMPULAN}

Dari hasil penelitian ini, sistem informasi Pesona Wisata Banyumas sangat membantu wisatawan untuk mencari informasi mengenai wisata yang ada ada di Kabupaten Banyumas. Dari pihak pengelola wisata juga terbantu karena wisatanya lebih terekspos dan tersebar luas sehingga banyak masyarakat yang tahu tentang wisata dan datang berkunjung ke wisata tersebut.

\section{SARAN}

Untuk penelitian selanjutnya disarankan untuk melakukan penambahan maps atau peta dan petunjuk arah dari lokasi wisata pada sistem informasi Pesona Wisata Banyumas untuk lebih memudahkan dan membantu wisatawan dalam berkunjung ke wisata yang ada di Kabupaten Banyumas.

\section{UCAPAN TERIMA KASIH}

Penulis mengucapkan terima kasih yang sedalam-dalamnya kepada semua pihak yang telah membantu dalam proses penulisan artikel ilmiah ini. Semoga artikel ilmiah ini dapat bermanfaat untuk semua pembaca.

\section{DAFTAR PUSTAKA}

[1] S. Darudiato and K. Setiawan, "Knowledge Management: Konsep dan Metodologi," Ultim. InfoSys, vol. IV, no. 1, pp. 11-17, 2013.

[2] Y. Akbar, "Knowledge Management System Pada Biro Administrasi Akademik Akademi Pariwisata Nusantara," J. String, vol. 3, no. 1, pp. 87-97, 2018.

[3] B. Sarayreh, A. Mardawi, and R. Dmour, "Comparative Study: The Nonaka Model of Knowledge Management," Int. J. Eng. Adv. Technol., vol. 1, no. 6, pp. 45-48, 2012.

[4] I. Nonaka, "Organizational Knowledge Creation," 1997.

[5] E. Turban, J. E. Aronsori, and T.-P. Liang, Decission Support System and Intelligence System 7th Ed. United States of America: Prentice Hall, 2007. 
[6] E. Randeree, "Knowledge Management: Securing The Future," $J$. Knowl. Manag., vol. 10, no. 4, pp. 145156, 2006.

[7] C. Connell, J. H. Klein, C. Loebbecke, and P. Powell, "Toward a Knowledge Management Consultation System," $J$. Knowl. Process Manag., vol. 8, no. 1, pp. 48-54, 2001.

[8] Sikki and M. Ilyas, "Manajemen Pengetahuan Dalam Ketahanan Pangan," J. LPPM Paradig., vol. 11, no. $1,2010$.
[9] I. B. Fernandez and R. Sabherwal, Knowledge Management : Systems and Processes. United States of America: M.E.Sharpe, Inc, 2010.

[10]L. F. Lai, “A Knowledge Engineering Approach To Knowledge Management," Int. J. Inf. Sci., vol. 177, no. 19, pp. 4072-4094, 2007.

[11]A. J. Rhem, UML For Developing Knowledge Management Systems. New York: Taylor \& Francis Group, 2006. 